\title{
Risk Factors for Breast Cancer among Japanese Women in Tokyo: A Case-Control Study
}

\author{
Kenji Wakai', Yoshiyuki Ohno', Susumu Watanabe'2, Goi Sakamoto ${ }^{3}$, \\ Fujio Kasumi ${ }^{4}$, Sadao Suzuki ${ }^{1}$, and Nakako Kubo-Fujiwara ${ }^{5}$
}

\begin{abstract}
To explore risk factors for female breast cancer, a hospital-based case-control study was conducted in Tokyo, from 1990 to 1991 . Information on potential risk factors was obtained by a selfadministered questionnaire from 5,084 out-patients. Of the patients, 300 incident breast cancer cases were recruited, and 900 age-matched controls were randomly selected. Following significant findings emerged: (a) A large number of livebirths was associated with a decreased risk in premenopausal women (relative risk (RR) for 3 or more biths relative to none: $0.24 ; 95 \%$ confidence interval $(\mathrm{Cl})$ : 0.08-0.65). (b) In premenopausal women, regular menstrual cycle increased the risk $(2.50 ; 1.16-5.38)$. (c) Current smokers experienced an increased risk $(1.63 ; 1.11-2.39)$. (d) Heavy weight was associated with a greater risk of postmenopausal breast cancer: RR for those weighing $70 \mathrm{~kg}$ or more relative to those weighing $50 \mathrm{~kg}$ or less being $4.82(1.53-15.2)$. (e) The later the age at first livebirth, the higher the postmenopausal breast cancer risk $(2.85 ; 1.16-6.99 ; 3.54$; 1.03-12.2 for ages of 30-34 and 35 years and more, respectively). J Epidemiol, $1994 ; 4$ : 65-71.
\end{abstract}

breast cancer, risk factor, case-control study, Japan

Many epidemiological studies have found several risk factors incriminated for female breast cancer. They include family history of breast cancer ${ }^{1-13)}$, history of benign breast disease $e^{2,4,8,9,14,15)}$, early menarche ${ }^{2,10,16-21)}$, late menopause $\mathrm{e}^{7-9,14-17,19,20,22)}$, late age at first birth/full-term pregnancy ${ }^{2,8-11,13,18,21,23-25)}$ and low parity/a small number of full-term pregnancies ${ }^{2,11,13,16,18,19,23,24,26,27)}$. Obesity or heavy weight is also an established risk factor for breast cancer among postmenopausal women ${ }^{2,13,20,28-31)}$.

Some studies have reported that breast-feeding has a protective effect against breast cancer, independently of other reproductive episodes ${ }^{2,12,23)}$. Whether drinking $^{3,5-8,10,11,13,15,21,22,27,32-35)}$ and smoking ${ }^{1,3,8,13,27,33,35-40)}$ habits are risk factors for this malignancy remains to be explored further.

In recent years, the incidence of female breast cancer has been increasing in Japan. The age-adjusted incidence (adjusted by World Population) was estimated to be 13.5 per 100,000 population in $1975^{41)}$ and 24.3 in $1985^{42)}$ This increase is conceivably ascribable to rapidly changing lifestyles among Japanese women. It is, therefore, of very importance and significance to explore the risk factors for breast cancer among Japanese women.

Nevertheless, a limited number of analytical epidemiological studies for breast cancer have recently been conducted in $\mathrm{Japan}^{3,13,35,43)}$. Then, we undertook a hospital-based case-control study of female breast cancer in Tokyo, and attempted to disclose risk factors in Japan.

\section{MATERIALS AND METHODS}

Information on potential risk factors was obtained by a self-administered questionnaire from all out-patients who visited Department of Breast Surgery, Cancer Institute, Tokyo from May 10, 1990, to May 31, 1991. Items surveyed were age, menopausal status, family history of breast

Received January 8, 1994 ; accepted March 24, 1994.

'Department of Preventive Medicine, Nagoya University School of Medicine, Nagoya, Japan.

2Department of Surgery, Cancer Institute Hospital, Tokyo, Japan.

${ }^{3}$ Department of Pathology, Cancer Institute, Tokyo, Japan.

'Department of Breast Surgery, Cancer Institute Hospital, Tokyo, Japan

${ }^{5}$ Department of Public Health, Nagoya City University Medical School, Nagoya, Japan.

Address for correspondence: Kenji Wakai, Department of Preventive Medicine, Nagoya University School of Medicine, 65 Tsurumai-cho Showa-ku Nagoya 466, Japan. 
Table 1. Age distribution of cases and controls by menopausal status.

\begin{tabular}{|c|c|c|c|c|c|c|c|c|c|c|c|c|}
\hline \multirow{3}{*}{ Age } & \multicolumn{4}{|c|}{ All women } & \multicolumn{4}{|c|}{ Premenopausal } & \multicolumn{4}{|c|}{ Postmenopausal } \\
\hline & \multicolumn{2}{|c|}{ Cases } & \multicolumn{2}{|c|}{ Controls } & \multicolumn{2}{|c|}{ Cases } & \multicolumn{2}{|c|}{ Controls } & \multicolumn{2}{|c|}{ Cases } & \multicolumn{2}{|c|}{ Controls } \\
\hline & $\mathrm{N}$ & $\%$ & $\mathbf{N}$ & $\%$ & $\mathbf{N}$ & $\%$ & $\mathbf{N}$ & $\%$ & $\mathbf{N}$ & $\%$ & $\mathbf{N}$ & $\overline{\%}$ \\
\hline $20-29$ & 6 & 2.0 & 18 & 2.0 & 6 & 3.5 & 17 & 3.5 & 0 & 0.0 & 1 & 0.2 \\
\hline $30-39$ & 25 & 8.3 & 75 & 8.3 & 25 & 14.7 & 71 & 14.7 & 0 & 0.0 & 4 & 1.0 \\
\hline $40-49$ & 131 & 43.7 & 393 & 43.7 & 119 & 70.0 & 352 & 72.7 & 12 & 9.2 & 41 & 9.9 \\
\hline $50-59$ & 81 & 27.0 & 243 & 27.0 & 20 & 11.8 & 44 & 9.1 & 61 & 46.9 & 199 & 47.8 \\
\hline $60-69$ & 40 & 13.3 & 120 & 13.3 & 0 & 0.0 & 0 & 0.0 & 40 & 30.8 & 120 & 28.8 \\
\hline $70-79$ & 14 & 4.7 & 46 & 5.1 & 0 & 0.0 & 0 & 0.0 & 14 & 10.8 & 46 & 11.1 \\
\hline 80 & 3 & 1.0 & 5 & 0.6 & 0 & 0.0 & 0 & 0.0 & 3 & 2.3 & 5 & 1.2 \\
\hline Total & 300 & 100.0 & 900 & 100.0 & 170 & 100.0 & 484 & 100.0 & 130 & 100.0 & 416 & 100.0 \\
\hline
\end{tabular}

Table 2. Relative risks (RR) and $95 \%$ confidence intervals (CI) of risk factors for breast cancer by menopausal status (1).

\begin{tabular}{|c|c|c|c|c|c|c|c|c|c|c|c|c|}
\hline & \multicolumn{4}{|c|}{ All women } & \multicolumn{4}{|c|}{ Premenopausal } & \multicolumn{4}{|c|}{ Postmenopausal } \\
\hline & \multicolumn{2}{|c|}{$\begin{array}{c}\text { Cases/ } \\
\text { Controls }\end{array}$} & & \multirow[t]{2}{*}{$95 \% \mathrm{CI}$} & \multicolumn{2}{|c|}{$\begin{array}{c}\text { Cases/ } \\
\text { Controls }\end{array}$} & \multirow[t]{2}{*}{ RR } & \multirow[t]{2}{*}{$95 \%$ CI } & \multicolumn{2}{|c|}{$\begin{array}{c}\text { Cases/ } \\
\text { Controls }\end{array}$} & \multirow[t]{2}{*}{ RR } & \multirow[t]{2}{*}{$95 \% \mathrm{CI}$} \\
\hline & & & & & & & & & & & & \\
\hline no & 275 & 843 & 1.00 & & 154 & 452 & 1.00 & & 121 & 391 & 1.00 & \\
\hline yes & 16 & 40 & 1.29 & $0.70-2.39$ & 11 & 20 & 1.64 & $0.70-3.83$ & 5 & 20 & 0.92 & $0.31-2.67$ \\
\hline \multicolumn{13}{|c|}{ History of benign breast disease } \\
\hline no & 261 & 779 & 1.00 & & 142 & 409 & 1.00 & & 119 & 370 & 1.00 & \\
\hline yes & 39 & 121 & 0.98 & $0.65-1.46$ & 28 & 75 & 1.05 & $0.63-1.78$ & 11 & 46 & 0.73 & $0.35-1.54$ \\
\hline \multicolumn{13}{|l|}{ Age at menarche } \\
\hline-12 & 64 & 181 & 1.00 & & 50 & 141 & 1.00 & & 14 & 40 & 1.00 & \\
\hline 13 & 76 & 207 & 1.09 & $0.72-1.63$ & 49 & 127 & 1.22 & $0.74-2.01$ & 27 & 80 & 0.90 & $0.40-2.05$ \\
\hline 14 & 57 & 205 & 0.82 & $0.54-1.26$ & 34 & 120 & 0.79 & $0.46-1.36$ & 23 & 85 & 0.74 & $0.32-1.71$ \\
\hline $15-$ & 99 & 294 & 0.94 & $0.63-1.42$ & 35 & 89 & 0.93 & $0.53-1.65$ & 64 & 205 & 0.85 & $0.40-1.77$ \\
\hline test for trend & & & & NS & & & & NS & & & & NS \\
\hline \multicolumn{13}{|c|}{ Age at menopause } \\
\hline-44 & & & & & & & & & 15 & 35 & 1.00 & \\
\hline $45-49$ & & & & & & & & & 32 & 104 & 0.65 & $0.29-1.45$ \\
\hline $50-54$ & & & & & & & & & 54 & 195 & 0.63 & $0.30-1.36$ \\
\hline $55-$ & & & & & & & & & 9 & 23 & 0.77 & $0.25-2.31$ \\
\hline test for trend & & & & & & & & & & & & NS \\
\hline \multicolumn{13}{|c|}{ Regularity of menstrual cycle } \\
\hline irregular & & & & & 29 & 103 & 1.00 & & & & & \\
\hline regular & & & & & 137 & 359 & 2.50 & $1.16-5.38$ & & & & \\
\hline \multicolumn{13}{|c|}{ Duration of menstrual cycle (days) } \\
\hline-27 & & & & & 40 & 94 & 1.00 & & & & & \\
\hline $28-29$ & & & & & 56 & 162 & 0.80 & $0.47-1.34$ & & & & \\
\hline $30-31$ & & & & & 21 & 66 & 0.66 & $0.34-1.28$ & & & & \\
\hline $32-$ & & & & & 2 & 11 & 0.50 & $0.10-2.58$ & & & & \\
\hline test for trend & & & & & & & & NS & & & & \\
\hline \multicolumn{13}{|l|}{ Age at first birth } \\
\hline-24 & 47 & 176 & 1.00 & & 26 & 91 & 1.00 & & 21 & 85 & 1.00 & \\
\hline $25-29$ & 68 & 254 & 1.03 & $0.67 \cdot 1.58$ & 41 & 151 & 0.93 & $0.51-1.69$ & 27 & 103 & 1.25 & $0.63-2.49$ \\
\hline $30-34$ & 28 & 65 & 1.64 & $0.92-2.94$ & 13 & 42 & 0.94 & $0.41-2.17$ & 15 & 23 & 2.85 & $1.16-6.99$ \\
\hline $35-$ & 10 & 18 & 2.17 & $0.91-5.20$ & 4 & 9 & 1.08 & $0.28-4.18$ & 6 & 9 & 3.54 & $1.03-12.2$ \\
\hline test for trend & & & & $\mathrm{p}<0.05$ & & & & NS & & & & $\mathrm{p}<0.05$ \\
\hline
\end{tabular}

All women : adjusted for age, menopausal status and other variables listed on the Table 2 and 3.

Premenopausal women and postmenopausal women : adjusted for age and other variables listed on the Table 2 and 3.

NS : not significant. 
Table 3. Relative risks (RR) and $95 \%$ confidence intervals (CI) of risk factors for breast cancer by menopausal status (2).

\begin{tabular}{|c|c|c|c|c|c|c|c|c|c|c|c|c|}
\hline \multirow{3}{*}{ Number of livebirth } & \multicolumn{4}{|c|}{ All women } & \multicolumn{4}{|c|}{ Premenopausal } & \multicolumn{4}{|c|}{ Postmenopausal } \\
\hline & \multicolumn{2}{|c|}{$\begin{array}{c}\text { Cases/ } \\
\text { Controls }\end{array}$} & \multirow{3}{*}{$\begin{array}{l}\text { RR } \\
1.00\end{array}$} & \multirow[t]{2}{*}{$95 \% \mathrm{CI}$} & \multicolumn{2}{|c|}{$\begin{array}{c}\text { Cases/ } \\
\text { Controls } \\
\end{array}$} & \multirow{3}{*}{$\begin{array}{l}\text { RR } \\
1.00\end{array}$} & \multirow[t]{2}{*}{$95 \% \mathrm{CI}$} & \multicolumn{2}{|c|}{$\begin{array}{c}\text { Cases/ } \\
\text { Controls }\end{array}$} & \multirow{3}{*}{$\begin{array}{l}\mathrm{RR} \\
1.00\end{array}$} & \multirow[t]{2}{*}{$95 \%$ CI } \\
\hline & & & & & & & & & & & & \\
\hline 0 & 46 & 115 & & & 34 & 58 & & & 12 & 57 & & \\
\hline 1 & 46 & 125 & 0.85 & $0.44-1.64$ & 24 & 65 & 0.52 & $0.21-1.32$ & 22 & 60 & 1.68 & $0.57-4.98$ \\
\hline 2 & 110 & 357 & 0.78 & $0.43-1.44$ & 68 & 223 & 0.40 & $0.17-0.95$ & 42 & 134 & 1.74 & $0.62-4.88$ \\
\hline $3-$ & 42 & 166 & 0.61 & $0.31-1.20$ & 13 & 69 & 0.24 & $0.08-0.65$ & 29 & 97 & 1.62 & $0.55-4.74$ \\
\hline test for trend & & & & NS & & & & NS & & & & NS \\
\hline \multicolumn{13}{|l|}{ Lactation } \\
\hline never & 62 & 162 & 1.00 & & 41 & 86 & 1.00 & & 21 & 76 & 1.00 & \\
\hline ever & 211 & 670 & 1.08 & $0.65-1.80$ & 112 & 365 & 1.21 & $0.59-2.50$ & 99 & 305 & 1.00 & $0.45-2.20$ \\
\hline \multicolumn{13}{|l|}{ Smoking } \\
\hline never smoked & 221 & 694 & 1.00 & & 123 & 364 & 1.00 & & 98 & 330 & 1.00 & \\
\hline ex-smoker & 15 & 52 & 0.91 & $0.49-1.70$ & 10 & 29 & 0.96 & $0.42-2.20$ & 5 & 23 & 0.80 & $0.28-2.32$ \\
\hline current smoker & 58 & 116 & 1.63 & $1.11-2.39$ & 34 & 79 & 1.23 & $0.75-2.03$ & 24 & 37 & 2.73 & $1.38-5.39$ \\
\hline \multicolumn{13}{|l|}{ Alcohol drinking } \\
\hline no & 187 & 563 & 1.00 & & 93 & 296 & 1.00 & & 94 & 267 & 1.00 & \\
\hline yes (current) & 109 & 306 & 1.04 & $0.77-1.39$ & 76 & 180 & 1.36 & $0.92-2.00$ & 33 & 128 & 0.71 & $0.42-1.19$ \\
\hline \multicolumn{13}{|l|}{ Height $(\mathrm{cm})$} \\
\hline-149 & 36 & 136 & 1.00 & & 14 & 42 & 1.00 & & 22 & 94 & 1.00 & \\
\hline $150-154$ & 102 & 311 & 1.22 & $0.78-1.92$ & 46 & 159 & 0.77 & $0.37-1.62$ & 56 & 152 & 1.81 & $0.98-3.34$ \\
\hline $155-159$ & 90 & 283 & 1.13 & $0.70-1.82$ & 58 & 180 & 0.71 & $0.34-1.49$ & 32 & 103 & 1.51 & $0.76-2.98$ \\
\hline 160 & 63 & 146 & 1.46 & $0.86-2.48$ & 47 & 97 & 1.08 & $0.49-2.37$ & 16 & 49 & 1.46 & $0.62-3.46$ \\
\hline test for trend & & & & NS & & & & NS & & & & NS \\
\hline \multicolumn{13}{|l|}{ Weight (kg) } \\
\hline-49 & 91 & 321 & 1.00 & & 43 & 177 & 1.00 & & 48 & 144 & 1.00 & \\
\hline $50-59$ & 140 & 421 & 1.18 & $0.86-1.62$ & 90 & 225 & 1.77 & $1.12-2.80$ & 50 & 196 & 0.77 & $0.47-1.26$ \\
\hline $60-69$ & 43 & 120 & 1.32 & $0.84-2.08$ & 23 & 63 & 1.59 & $0.82-3.05$ & 20 & 57 & 1.09 & $0.54-2.21$ \\
\hline 70 & 17 & 18 & 3.06 & $1.47-6.37$ & 7 & 12 & 2.76 & $0.96-7.89$ & 10 & 6 & 4.82 & $1.53-15.2$ \\
\hline test for trend & & & & $\mathrm{p}<0.05$ & & & & $\mathrm{p}<0.05$ & & & & NS \\
\hline
\end{tabular}

All women : adjusted for age, menopausal status and other variables listed on the Table 2 and 3.

Premenopausal women and postmenopausal women : adjusted for age and other variables listed on the Table 2 and 3.

NS : not significant.

cancer, history of benign breast disease, regularity and duration of menstrual cycle (for premenopausal women), ages at menarche and menopause, age at first birth, number of livebirths, episodes of lactation, smoking and drinking habits, height and weight. This information has been collected from all out-patients before examination, that is, prior to diagnosis.

Of the 5,084 female patients who visited the department during the study period, 314 were newly diagnosed as having breast cancer histologically. Of 314 breast cancer patients, we excluded 11 patients with missing information on menopausal status, one patient under 25 years old, and 2 patients with history of other malignant tumors. Thus, 300 incident patients were eligible cases for the present study.

Controls were randomly selected from the remaining 4,770 patients without breast cancer, excluding those with missing information on menopausal status and/or with history of other malignant tumors. Three controls per case were randomly selected, matching each other for age (as nearest as possible). Almost all the controls (97.6\%) were exactly matched for age, while $1.8 \%$ and $0.7 \%$ of them within $\pm 1-3$ and \pm 46 years, respectively. Table 1 shows the age distribution of the study subjects ( 300 cases and 900 controls) by menopausal status. The mean ages ( \pm standard deviations) of the cases and controls were $50.8 \pm 10.7$ and $50.7 \pm 10.5$ years, respectively.

All analyses were performed for premenopausal and postmenopausal women, separately or totally. The RRs by menopausal status were obtained using unconditional multiple logistic regression analysis ${ }^{44}$ adjusted for age and other variables potentially confounded, irrespective of the matching. Unconditional multiple logistic regression, not conditional one, was also applied to the analysis for all 
Table 4. Relative risks (RR) and $95 \%$ confidence intervals (CI) for breast cancer according to number of cigarettes smoked per day by menopausal status.

\begin{tabular}{|c|c|c|c|c|c|c|c|c|c|c|c|c|}
\hline & \multicolumn{4}{|c|}{ All women } & \multicolumn{4}{|c|}{ Premenopausal } & \multicolumn{4}{|c|}{ Postmenopausal } \\
\hline & \multicolumn{2}{|c|}{$\begin{array}{c}\text { Cases/ } \\
\text { Controls }\end{array}$} & \multirow[t]{2}{*}{ RR } & \multirow[t]{2}{*}{$95 \% \mathrm{CI}$} & \multicolumn{2}{|c|}{$\begin{array}{c}\text { Cases/ } \\
\text { Controls }\end{array}$} & \multirow[t]{2}{*}{ RR } & \multirow[t]{2}{*}{$95 \% \mathrm{CI}$} & \multicolumn{2}{|c|}{$\begin{array}{c}\text { Cases/ } \\
\text { Controls }\end{array}$} & \multirow[t]{2}{*}{ RR } & \multirow[t]{2}{*}{$95 \% \mathrm{CI}$} \\
\hline & & & & & & & & & & & & \\
\hline 0 & 236 & 746 & 1.00 & & 133 & 393 & 1.00 & & 103 & 353 & 1.00 & \\
\hline $1-19$ & 35 & 74 & 1.67 & $1.06-2.63$ & 21 & 54 & 1.21 & $0.67-2.19$ & 14 & 20 & 3.11 & $1.37-7.10$ \\
\hline 20 & 18 & 38 & 1.44 & $0.77-2.68$ & 12 & 22 & 1.54 & $0.69-3.44$ & 6 & 16 & 1.68 & $0.56-5.10$ \\
\hline test for trend & & & & $\mathrm{p}<0.05$ & & & & NS & & & & $\mathrm{p}<0.05$ \\
\hline
\end{tabular}

All women: adjusted for age, menopausal status and other variables listed on the Table 2 and 3.

Premenopausal women and postmenopausal women: adjusted for age and other variables listed on the Table 2 and 3. NS : not significant.

women, because the age matching status was not completely uniform over the pairs. Tests for trend in the logistic analysis were obtained by categorizing the exposure variable and treating the scored variable as a continuous variable.

In the multivariate analysis, study subjects with missing information were also included as an additional category. The additional categories, in which missing information accounted for more than $10 \%$, were proved not to be significantly associated with breast cancer risk; indicating that such inclusions would not distort the RRs obtained substantially.

\section{RESULTS}

Table 2 and 3 summarize the RRs obtained by the logistic regression analyses.

Family history of breast cancer and history of benign breast disease were found neither to increase nor to decrease breast cancer risk, though family history demonstrated somewhat greater relative risk than unity $(1.64)$ in premenopausal women.

Ages at menarche and menopause were not significantly associated with breast cancer risk, though regular menstrual cycle increased the risk in premenopausal women. Decreasing risk of breast cancer with increasing duration of menstrual cycle was also suggested.

Late age at first birth was positively associated with breast cancer risk in postmenopausal women; the RR being 2.85 (95\% CI : 1.16-6.99) for age of 30-34 years, and 3.54 (1.03-12.2) for that of 35 years or older. A large number of livebirths was associated with a decreased risk, particularly in premenopausal women; the RR relative to none was 0.40 ( $95 \% \mathrm{CI}: 0.17-0.95$ ) for 2 livebirths and 0.24 $(0.08-0.65)$ for 3 or more livebirths. "Ever lactated" was found neither to increase nor to decrease the risk.

Current smokers were found to be at an increased risk particularly for postmenopausal breast cancer (RR : 1.63; $95 \% \mathrm{CI}: 1.11-2.39$ for all women and $2.73 ; 1.38-5.39$ for postmenopausal women), though the dose-response relationship between the number of cigarettes smoked per day and the risk was not clear (Table 4). Current drinkers were likely to be at an increased risk in premenopausal women (RR : $1.36 ; 95 \% \mathrm{CI}: 0.92-2.00$ ).

Heavy weight was associated with a significantly greater risk, particularly for postmenopausal breast cancer; the RR for those weighing $70 \mathrm{~kg}$ or more relative to less than $50 \mathrm{~kg}$ was 4.82 (95\% Cl 1.53-15.2). No significant association of height with breast cancer risk was detected.

\section{DISCUSSION}

When assessing our findings described above, one methodological limitation should be kept in mind.

Our control series might more prevalently include women with benign breast disease than general female population, because we selected, though randomly, the controls from women who sought for breast examination at the department of breast surgery and were later proved not to have breast cancer. Usually, definite diagnosis is not always made in the clinical practice when malignancy is not suspected. Therefore, we could not systematically exclude women with benign breast disease from our controls. However, patients with histologically confirmed benign breast disease are known to comprise less than $5 \%$ among all the patients without breast cancer in the department (unpublished data). Symptomatic (not biopsied) benign breast disease was also known not to be so related to the risk factors for breast cancer as biopsied one ${ }^{45}$. Since our control series were selected from the patients in the same department where the cases were identified, then study subjects shared similar demographic characteristics each other. The data collection before examination could reduce information biases such as recall one. Therefore, despite the limitation mentioned above, the present control series would be useful as a reference group.

Family history of breast cancer is consistently incriminated as a risk factor for female breast cancer ${ }^{1-13)}$. Our 
failure in finding an association with family history may be partly ascribable to excessive inclusion of women with benign breast disease in our control series, since family history of breast cancer is known to be positively associated with history of benign breast disease ${ }^{45-47}$.

Both early menarche ${ }^{2,10,16-21)}$ and late menopause $^{7-9,14-17,19,20,22)}$ are well-established risk factors. In Japan, however, significant relevance of early menarche and late menopause to breast cancer risk has not always been detected ${ }^{13,35,43)}$, likewise our study.

Decreasing risk of breast cancer with increasing duration of menstrual cycle has been suggested in some studies ${ }^{2,48}$, as did our study. We found a significant association of regular menstrual cycle with an increased premenopausal breast cancer risk, but this was not detected in previous studies $^{17,35)}$. These two particular findings on menstruation may suggestively indicate that breast cancer risk appears to be directly related to the cumulative number of regular ovulatory cycles $^{48,499}$.

Many studies have demonstrated that late age at first birth/full-term pregnancy is linked to the risk of breast cancer $2,8-11,13,18,21,23-25)$. Our study also detected a larger RR for later age at first birth, particularly in postmenopausal women.

Several recent studies have noted that frequent full-term pregnancy or birth has a protective effect against breast cancer, independently of age at first birth/full-term pregnancy $2,16,19,23,24,26)$. In our study also, a large number of livebirths was independently associated with a decreased risk, particularly in premenopausal women. This finding may essentially indicate that a recently increasing breast cancer incidence in Japan is partly related to the rapidly declined birth rate ${ }^{50}$.

Ever-lactated women were not at a significantly smaller risk of breast cancer, when the covariates were adjusted. Since almost studies, which detected the independent protective effect of breast-feeding, examined the relationship between lactation period and breast cancer risk ${ }^{2,12,23)}$, then further investigations focusing on the period of lactation would be required to assess the effect of lactation more properly.

An association of smoking habits with breast cancer risk still remains to be inconclusive. Most studies have found no clear association $3,8,13,27,33,36-38,40)$, while some investigators have suggested an unfavorable effect of smoking habits on breast cancer ${ }^{1,35,39)}$. In the present study, smoking habits were found to be associated with breast cancer risk, likewise a previous study conducted in Nagoya, Japan ${ }^{35}$. In our study, we failed to detect clear dose-response relationship between the number of cigarettes smoked per day and breast cancer risk. Nevertheless, more detailed studies will be warranted on smoking habits, since our findings certainly indicate a positive association of smoking habits with breast cancer risk in females in Japan.
A positive association between alcohol consumption and breast cancer has been reported in many ${ }^{3,5,6,6,8,11,15,21,22,34)}$, but not all $7,10,13,27,32,33,35)$, epidemiological studies. The present study, however, did not show a significantly larger RR for current drinkers. Studies that take an amount of alcohol consumed into consideration will be required to assess this association more properly.

For anthropometric factors, we found women with heavy weight to be at significantly greater risk of postmenopausal breast cancer, which is in good agreement with previous findings ${ }^{2,13,28,30,31}$. Several studies have reported a positive association between height and female breast cancer ${ }^{20,28,51}$, but we did not find such an association.

In short, our study disclosed the following major findings. (a) A large number of livebirths was associated with a decreased risk, particularly in premenopausal women; (b) In premenopausal women, regular menstrual cycle significantly increased the risk, and its increasing duration suggestively decreased the risk; (c) Current smokers experienced a significantly larger RR, particularly in postmenopausal women; (d) Heavy weight was associated with a significantly greater risk of postmenopausal breast cancer; (e) The later the age at first livebirth, the higher the postmenopausal breast cancer risk; (f) Ages at menarche and menopause, lactation, drinking habits and height were not independently associated with female breast cancer risk.

\section{REFERENCES}

1. Brownson RC, Blackwell CW, Pearson DK, et al. Risk of breast cancer in relation to cigarette smoking. Arch Intern Med, $1988 ; 148$ : 140-144.

2. Yuan J-M, Yu MC, Ross RK, Gao Y-T, Henderson BE. Risk factors for breast cancer in Chinese women in Shanghai. Cancer Res, 1988 ; 48 : 1949-1953.

3. Kato I, Tominaga S, Terao C. Alcohol consumption and cancers of hormone-related organs in females. Jpn J Clin Oncol, $1989 ; 19:$ 202-207.

4. Siskind V, Schofield F, Rice D, Bain C. Breast cancer and breastfeeding : results from an Australian case-control study. Am J Epidemiol, 1989; 130 : 229-236.

5. Young TB. A case-control study of breast cancer and alcohol consumption habits. Cancer, 1989 ; 64 : 552-558.

6. Toniolo P, Riboli E, Protta F, Charrel M, Cappa APM. Breast cancer and alcohol consumption : a case-control study in Northern Italy. Cancer Res, 1989 ; $49: 5203-5206$.

7. Rosenberg L, Palmer JR, Miller DR, Clarke EA, Shapiro S. A case-control study of alcoholic beverage consumption and breast cancer. Am J Epidemiol, 1990 ; 131 ; 6-14.

8. Nasca PC, Baptiste MS, Field NA, et al. An epidemiological case-control study of breast cancer and alcohol consumption. Int J Epidemiol, 1990; 19 : 532-538.

9. Segala C, Gerber M, Richardson S. The pattern of risk factors for breast cancer in a Southern France population. Interest for a stratified analysis by age at diagnosis. $\mathrm{Br} J$ Cancer, $1991 ; 64: 919-925$.

10. Simon MS, Carman W, Wolfe R, Schottenfeld D. Alcohol consumption and the risk of breast cancer : a report from the 
Tecumseh Community Health Study. J Clin Epidemiol, 1991; 44 : 755-761.

11. Ferraroni M, Decarli A, Willett WC, Marubini E. Alcohol and breast cancer risk: a case-control study from Northern Italy. Int J Epidemiol, 1991; 20: 859-864.

12. Yoo K-Y, Tajima K, Kuroishi T, et al. Independent protective effect of lactation against breast cancer: a case-control study in Japan. Am J Epidemiol, 1992 ; 135: 726-733.

13. Kato I, Miura S, Kasumi F, et al. A case-control study of breast cancer among Japanese women: with special reference to family history and reproductive and dietary factors. Breast Cancer Res Treat, 1992; 24 : 51-59.

14. Tao S-C, Yu MC, Ross RK, Xiu K-W. Risk factors for breast cancer in Chinese women of Beijing. Int $\mathrm{J}$ Cancer, $1988 ; 42: 495-498$.

15. Richardson S, de Vincenzi I, Pujol H, Gerber M. Alcohol consumption in a case-control study of breast cancer in Southern France. Int J Cancer, 1989; $44: 84-89$.

16. Ewertz $M$, Duffy $S W$. Risk of breast cancer in relation to reproductive factors in Denmark. Br J Cancer, 1988; 58 : 99-104.

17. Kvåle G, Heuch I. Menstrual factors and breast cancer risk. Cancer, 1988 ; 62 : 1625-1631.

18. Bouchardy C, Lê MG, Hill C. Risk factors for breast cancer according to age at diagnosis in a French case-control study. J Clin Epidemiol, 1990; $43:$ 267-275.

19. Yu S-Z, Lu R-F, Xu D-D, Howe GR. A case-control study of dietary and nondietary risk factors for breast cancer in Shanghai. Cancer Res, 1990; 50: 5017-5021.

20. Hsieh C-C, Trichopoulos D, Katsouyanni K, Yuasa S. Age at menarche, age at menopause, height and obesity as risk factors for breast cancer: associations and interactions in an international case-control study. Int J Cancer, 1990; 46: 796-800.

21. Gapstur SM, Potter JD, Sellers TA, Folsom AR. Increased risk of breast cancer with alcohol consumption in postmenopausal women. Am J Epidemiol, 1992; 136, 12211231.

22. Zaridze D, Lifanova Y, Maximovitch D, Day NE, Duffy SW. Diet, alcohol consumption and reproductive factors in a casecontrol study of breast cancer in Moscow. Int $\mathbf{J}$ Cancer, $1991 ; 48: 493-501$.

23. Layde PM, Webster LA, Baughman AL, et al. The independent associations of parity, age at first full term pregnancy, and duration of breastfeeding with the risk of breast cancer. J Clin Epidemiol, 1989 ; 42 : 963-973.

24. Ewertz M, Duffy SW, Adami H-O, et al. Age at first birth, parity and risk of breast cancer : a meta-analysis of 8 studies from the Nordic countries. Int J Cancer, 1990; 46: 597603.

25. la Vecchia C, Negri E, Franceschi S, Parazzini F. Longterm impact of reproductive factors on cancer risk. Int $\mathrm{J}$ Cancer, $1993 ; 53: 215-219$.

26. Leon DA. A prospective study of the independent effects of parity and age at first birth on breast cancer incidence in England and Wales. Int J Cancer, 1989; 43: 986-991.

27. Schatzkin A, Carter CL, Green SB, et al. Is alcohol consumption related to breast cancer? Results from the Framingham Heart Study. J Natl Cancer Inst, 1989; 81 : 31-35.

28. Swanson CA, Brinton LA, Taylor PR, et al. Body size and breast cancer risk assessed in women participating in the Breast Cancer Detection Demonstration Project. Am J Epidemiol, 1989; 130: 1133-1141.

29. Tretli S. Height and weight in relation to breast cancer morbidity and mortality. A prospective study of 570,000 women in Norway. Int $\mathbf{J}$ Cancer, $1989 ; 44: 23-30$.

30. Parazzini F, la Vecchia C, Negri E, et al. Anthropometric variables and risk of breast cancer. Int J Cancer, 1990; 45 : $397-402$.

31. Sellers TA, Kushi LH, Potter JD, et al. Effect of family history, body-fat distribution, and reproductive factors on the risk of postmenopausal breast cancer. N Engl J Med, 1992 ; 326: 1323-1329.

32. Chu SY, Lee NC, Wingo PA, Webster LA. Alcohol consumption and the risk of breast cancer. Am J Epidemiol, $1989 ; 130: 867-877$.

33. Meara J, McPherson $K$, Roberts $M$, Jones L, Vessey $M$. Alcohol, cigarette smoking and breast cancer. $\mathrm{Br} \mathbf{J}$ Cancer, $1989 ; 60: 70-73$.

34. Howe $G$, Rohan $T$, Decarli $A$, et al. The association between alcohol and breast cancer risk: evidence from the combined analysis of six dietary case-control studies. Int $\mathbf{J}$ Cancer, $1991 ; 47$ : 707-710.

35. Yoo K-Y, Tajima K, Kuroishi T, et al. Life-style in relation to the risk of breast cancer. J Epidemiol (Suppl), 1992; 2 : S155-S165.

36. Rohan TE, Baron JA. Cigarette smoking and breast cancer. Am J Epidemiol, 1989 ; 129: 36-42.

37. Schechter MT, Miller AB, Howe GR, et al. Cigarette smoking and breast cancer: case-control studies of prevalent and incident cancer in the Canadian National Breast Screening Study. Am J Epidemiol, 1989; 130 : 213-220.

38. London SJ, Colditz GA, Stampfer MJ, et al. Prospective study of smoking and the risk of breast cancer. J Natl Cancer Inst, 1989; 81 : 1625-1631.

39. Chu SY, Stroup NE, Wingo PA, et al. Cigarette smoking and the risk of breast cancer. Am J Epidemiol, 1990 ; 131 : $244-253$.

40. Field NA, Baptiste MS, Nasca PC, Metzger BB. Cigarette smoking and breast cancer. Int J Epidemiol, 1992; 21 : 842-848.

41. The Research Group for Population-based Cancer Registration. Cancer incidence in Japan, 1975-1979. The Osaka Cancer Registry, Osaka, 1984: 20-21.

42. Research Group for Population-based Cancer Registration in Japan. Cancer incidence and incidence rates in Japan in 1985-Estimates based on data from seven population-based cancer registries-. Jpn J Clin Oncol, 1990; $20: 212-218$.

43. Hirohata T, Shigematsu T, Nomura AMY, et al. Occurrence of breast cancer in relation to diet and reproductive history: a case-control study in Fukuoka, Japan. Natl Cancer Inst Monogr, 1985; $69: 187-190$.

44. Breslow NE, Day NE. Unconditional logistic regression for large strata. In; Davis W, ed. Statistical Methods in Cancer Research, vol 1. IARC, Lyon, 1980: 192-246.

45. Hislop TG, Elwood JM. Risk factors for benign breast disease : a 30-year cohort study. Can Med Assoc J, 1981; 124: 283-291.

46. Pastides H, Kelsey JL, Holford TR, LiVolsi VA. An epidemiologic study of fibrocystic breast disease with reference to ductal epithelial atypia. Am J Epidemiol, 1985; 121: 440-447.

47. Berkowitz GS, Kelsey JL, LiVolsi VA, et al. Risk factors for fibrocystic breast disease and its histopathologic components. J Natl Cancer Inst, $1985 ; 75: 43-50$.

48. Olsson H, Landin-Olsson M, Gullberg B. Retrospective assessment of menstrual cycle length in patients with breast cancer, in patients with benign breast disease, and in women without breast disease. J Natl Cancer Inst, 1983; 70 : 17-20. 
49. Henderson BE, Ross RK, Judo HL, Krailo MD, Pike MC. Do regular ovulatory cycles increase breast cancer risk? Cancer, 1985; 56: 1206-1208.

50. Ministry of Health and Welfare of Japan. Vital Statistics of Japan 1991, vol 1. Kousei Toukei Kyoukai, Tokyo, 1993 :
80-81 (in Japanese).

51. Vatten LJ, Kvinnsland S. Body height and risk of breast cancer. A prospective study of 23,831 Norwegian women. Br J Cancer, 1990; 61: 881-885. 